\title{
Reconfigurando as redes institucionais: Relações interfirmas, trabalho e educação na industria de linha branca*
}

\author{
Leda Gitahy, Adriana Marques da Cunha \\ e Alessandra Rachid**
}

\begin{abstract}
RESUMO: Este trabalho analisa a difusão de inovações tecnológicas e organizacionais na cadeia produtiva de linha branca a partir de pesquisa realizada em empresas localizadas na região de Campinas/SP no período 1996-1997. Discute-se como o processo de reestruturação produtiva provoca a reconfiguração das relações interfirmas e das relações entre empresas e diferentes instituições, especialmente do sistema educacional.
\end{abstract}

Palavras-chave: Relações interfirmas, trabalho, educação, indústria de linha branca

\section{Introdução}

O processo de reestruturação industrial em nível internacional, associado à globalização da economia, está induzindo movimentos simultâneos de destruição/reconstrução das relações produtivas tradicionais. Atualmente, assistem-se a mudanças significativas nas relações interfirmas em diferentes cadeias produtivas, nos mercados de produtos e de trabalho, na mobilidade dos trabalhadores e nos requerimentos de qualificação. Essas mudanças têm levado a um renova-

* Este artigo é produto da pesquisa "Reestruturação produtiva trabalho e educação: Os efeitos sociais da terceirização industrial em três regiões do país", Cedes/Finep/CNPq, coordenada por Alice Rangel de Paiva Abreu e José Ricardo Ramalho (PPGS/IFCS/UFRJ), Leda Gitahy (DPCT/IG/Unicamp) e Roberto Ruas (PPGA-UFRGS), (RJ, SP, RS), 1995-97. Agradecemos a contribuição de Fabiane Santana Previtalli (bolsista do projeto), que participou da pesquisa realizada na região de Campinas.

** Leda Gitahy é professora do DPCT/IG/Unicamp, Adriana Marques da Cunha (bolsista do projeto) é doutoranda do IE/Unicamp e Alessandra Rachid é professora do DEP/UFSCar. 
do interesse pela forma em que se articulam a organização da produção e do trabalho, as condições de emprego e as exigências de qualificação, o que torna necessário a análise simultânea do que ocorre dentro e fora das empresas. Nesse sentido, um tema relevante passa a ser o da construção social das redes produtivas e suas novas formas de articulação institucional ${ }^{1}$.

Este enfoque permite evitar o determinismo, econômico ou tecnológico (presente em muitos estudos sobre "efeitos" das novas tecnologias ou da globalização e, por ende, a idéia da inevitabilidade das mudanças em um ou outro sentido), e pensar as transformações em curso em termos de múltiplas escolhas de atores concretos diante de condições sociais e econômicas dadas. Ou seja, ao estudar o processo de difusão de inovações, deve-se considerar como e por que certas idéias e formas de fazer, e não outras, são as que se afirmam num determinado período (pergunta, aliás, mais fácil de responder a posteriori do que a priori) e como elas se institucionalizam.

O objetivo deste trabalho é, a partir de pesquisa realizada em um segmento da cadeia produtiva da indústria de linha branca, ${ }^{2}$ localizada na região de Campinas, ${ }^{3}$ verificar em que medida o processo de reestruturação em curso nessa indústria, de âmbito nacional e internacional, provoca mudanças no interior das empresas que, por sua vez, passam a implicar uma reconfiguração das relações interfirmas e das relações entre as empresas e as diferentes instituições, especialmente do sistema educacional. Ao trabalhar com o conceito de cadeia produtiva, ${ }^{4}$ que orienta o recorte utilizado para a escolha da amostra, pretende-se analisar não somente a difusão de inovações tecnológicas e organizacionais no interior das empresas estudadas, mas também como, e em que medida, este conjunto de inovações provoca uma redefinição da divisão do trabalho (estratégias de focalização associadas a movimentos de externalização/internalização de atividades) no interior da cadeia produtiva, modificando sua estrutura e forma de organização.

A pesquisa foi iniciada na planta de uma grande empresa produtora de refrigeradores e lavadoras de roupa, recentemente adquirida por um dos principais grupos internacionais da indústria de eletrodomésticos (empresa "montadora", que vende diretamente ao comércio varejista). A pesquisa prosseguiu em seu principal fornecedor de compressores, parte-chave de refrigeradores e freezers (fornecedor de primeira linha), a partir do qual escolheram-se dez de seus pe- 
quenos e médios fornecedores (fornecedores de segunda linha) localizados na mesma região (figura 1).

Figura 1: Posição das empresas na cadeia produtiva de linha branca

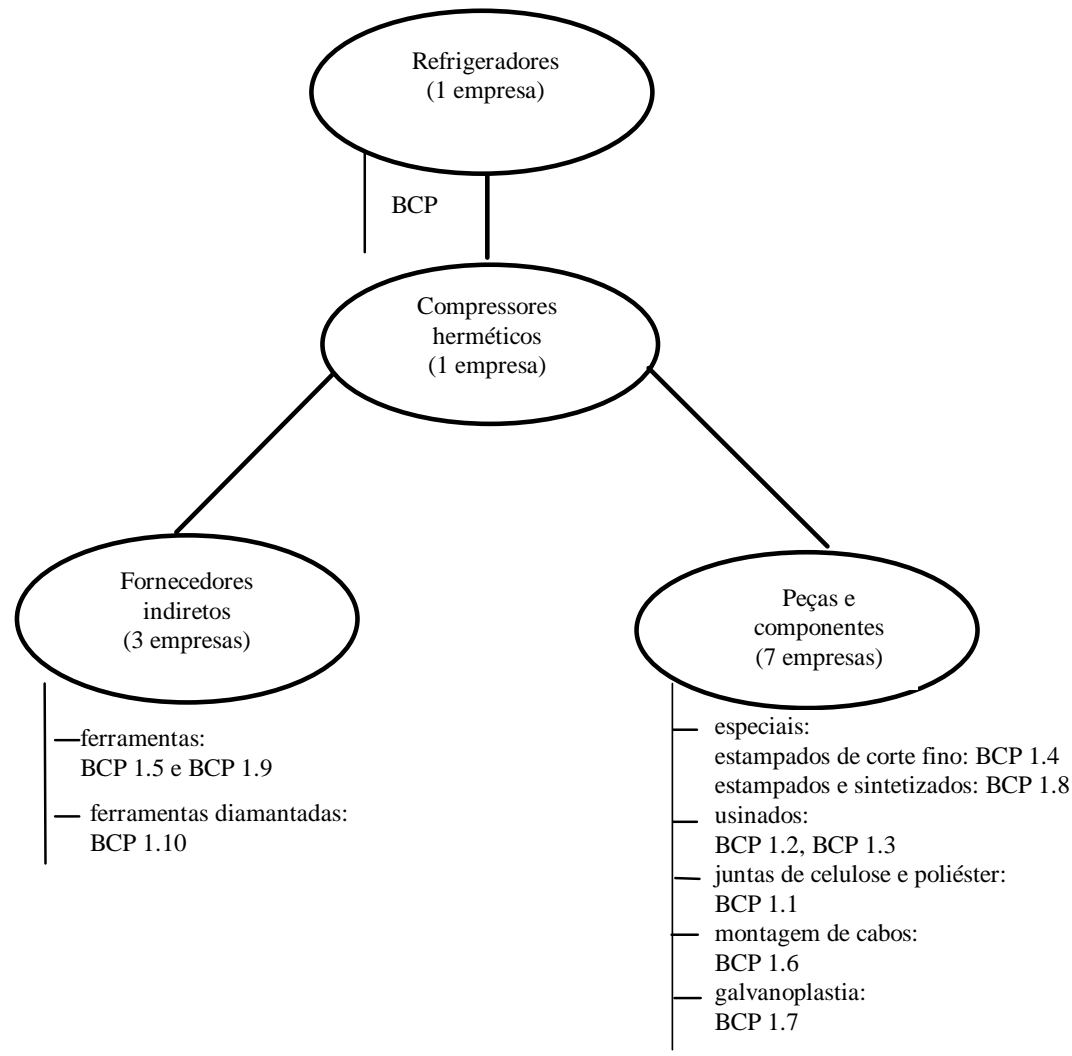

A amostra é composta por duas grandes empresas com plantas de 2.000 e 4.600 funcionários e faturamento de US\$ 450 milhões e US $\$ 360$ milhões, respectivamente, e por dez fornecedores diretos e indiretos $^{5}$ da BCP 1.

Este conjunto é formado por empresas pequenas e médias, com plantas de 10 a 188 empregados e faturamento de US $\$ 300$ mil a US\$ 19 milhões (tabela 1). Somente duas empresas deste grupo são fornecedoras exclusivas da cadeia de linha branca. Uma das empresas 


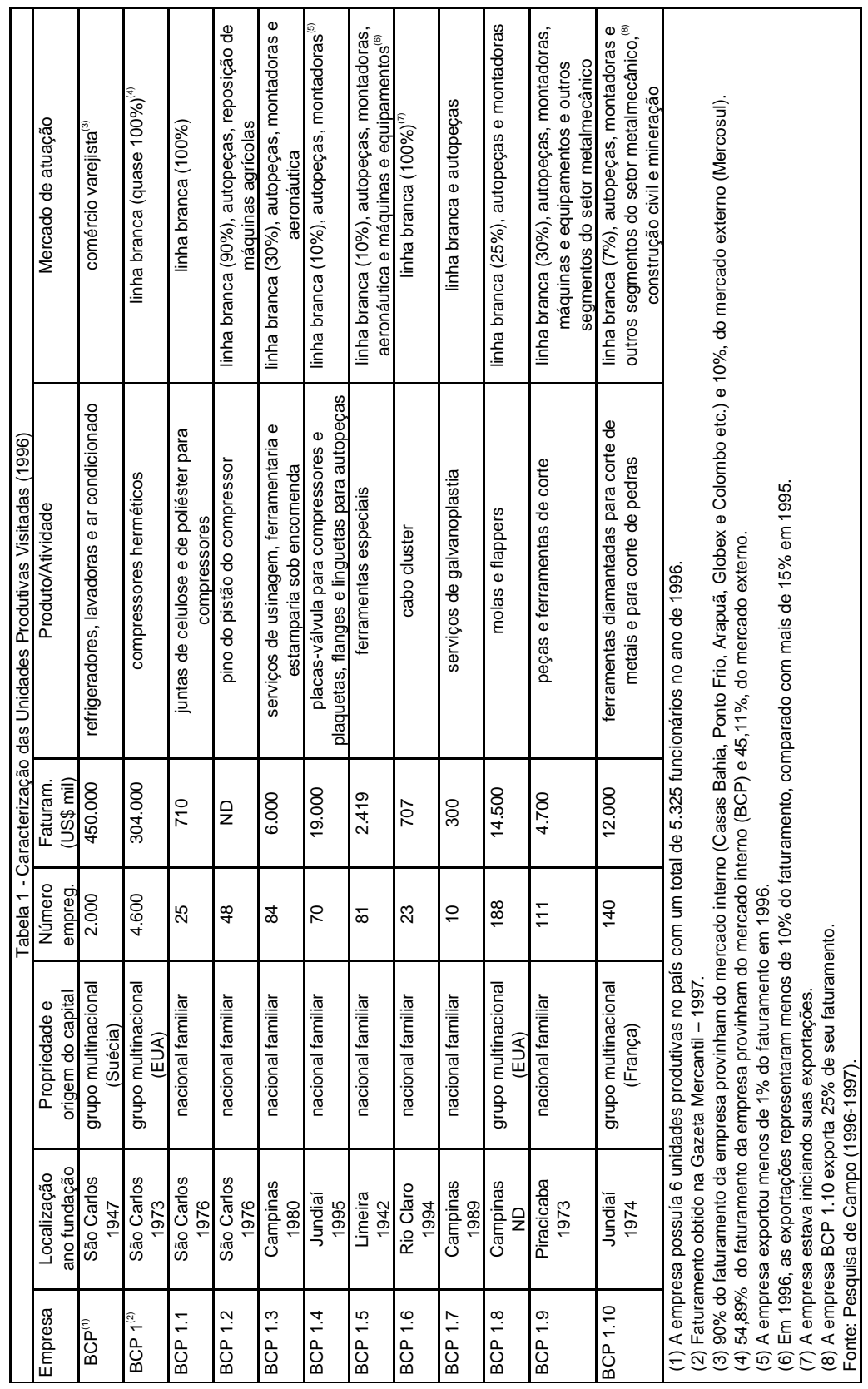


tem $90 \%$ de seu faturamento dependendo das vendas para as empresas de linha branca e, nas demais, essa porcentagem varia de $7 \%$ a $30 \%$. Essas empresas fornecem também para outros segmentos da indústria metalmecânica, destacando-se sua inserção na cadeia automotiva.

Uma das principais características das pequenas e médias empresas é sua inserção no cruzamento de diversas cadeias de produto da indústria metalmecânica, onde elas se encontram "espremidas" entre grandes clientes e grandes fornecedores. Como regra geral, elas evitam depender de um único cliente. ${ }^{6}$

Do ponto de vista da origem do capital e da propriedade, além das duas grandes empresas atualmente pertencentes a grandes grupos multinacionais, encontram-se entre os fornecedores, atuando em nichos especializados, duas empresas de origem alemã e familiar, que vieram para o Brasil acompanhando seus grandes clientes, sendo posteriormente adquiridas por grandes grupos estrangeiros. As demais empresas da amostra são todas de origem nacional e familiar. Somente a empresa que encabeça a cadeia estudada é uma sociedade anônima, enquanto todas as demais são de capital limitado.

No que se refere à gestão, vale destacar que, enquanto as grandes empresas estão reduzindo níveis hierárquicos e enxugando a gerência tradicional no âmbito de seus processos de reestruturação, as pequenas e médias, em seu processo de crescimento, estão criando algo parecido com um embrião de uma gerência profissionalizada, especialmente nas áreas mais técnicas, como a qualidade e a engenharia, ainda que reduzindo o número de trabalhadores indiretos tradicionais (serviços de apoio). Outro ponto que vale mencionar é a divisão do trabalho nas empresas familiares: homens (da família), responsáveis pela parte técnica, e as mulheres (da família), responsáveis pela parte administrativa, especialmente financeira, fenômeno observado por Capechi (1989) na chamada "Terceira Itália".

É interessante observar que as trajetórias das empresas confundem-se com a história da industrialização de seus respectivos setores de atividade (via substituição de importações até os anos 80 e abertura do mercado a partir dos anos 90 ). A BCP surge como uma empresa nacional no final dos anos 40 , sendo adquirida por um grande grupo nacional na fase de concentração dessa indústria nos anos 70 e, finalmente, por um grande grupo internacional em meados dos 
anos 90, acompanhando o movimento de concentração e internacionalização da indústria mundial de eletrodomésticos. A BCP 1 foi criada em 1973 através de uma associação da empresa nacional então proprietária da BCP, em cuja fábrica de compressores, localizada em São Carlos/SP, instalou-se a nova empresa, com um grupo norte-americano, também fabricante de produtos de linha branca no Brasil, e uma empresa argentina. Uma das maiores empresas mundiais de compressores herméticos de origem norte-americana acabou comprando parte da empresa em 1978, tornando-se responsável pelo licenciamento da tecnologia utilizada. Esta multinacional assumiu o controle total da empresa em 1984, transformando-a em sua maior subsidiária fora de seu país de origem.

Por sua vez, a criação das pequenas empresas passa por várias fases, associadas à expansão industrial a partir do final dos anos 60 , à crise econômica e à reestruturação "defensiva" de grandes empresas, acompanhada por processos de desverticalização, a partir do início dos anos 80 , bem como à intensificação da externalização de atividades por grandes empresas em processo de reestruturação a partir dos anos 90 . O processo de desverticalização de grandes empresas começou nos anos 80 , estimulando a criação de pequenas empresas em nichos identificados por ex-funcionários, incentivados ou não por suas empresas de origem.

A maioria dos fundadores das pequenas e médias empresas, especialmente daquelas formadas até meados dos anos 80 , é proveniente do sistema de formação profissional (Senai - Serviço Nacional de Aprendizagem Industrial - e Escolas Técnicas), com experiência profissional anterior em grandes empresas da região. É interessante pensar este fenômeno em termos de redes de inovação, ou seja, da importância do papel do ambiente formado por essas instituições na constituição de um tipo de "cultura industrial" que parece estimular o interesse na criação de "negócios próprios" e no investimento em inovações tecnológicas (este tipo de empresário está entre os primeiros a adquirir máquinas de comando numérico nos anos 80).

Por fim, outros fenômenos interessantes da história das pequenas e médias empresas devem ser destacados: a formação universitária da segunda geração de empresários e o papel "modernizador" das empresas que sobrevivem. Um novo perfil de proprietário começa a surgir já no final da década de 1980: as empresas BCP 1.6 e BCP 1.7 foram fundadas por engenheiros que haviam trabalhado em grandes empresas $\mathrm{e}$ que, possivelmente, foram afetados pela onda de reestruturação. É inte- 
ressante contrastar essas duas empresas, que se caracterizam por investir em processos simples e intensivos em mão-de-obra e cujas trajetórias estão estreitamente associadas a processos de externalização, com as empresas fundadas por ex-operários especializados, que passaram a se dedicar às atividades mais "nobres" de usinagem e ferramentaria e cujas trajetórias estão marcadas pela "cultura de inovação".

\section{Transformações na indústria de linha branca}

Durante as duas últimas décadas, a indústria mundial de eletrodomésticos ${ }^{7}$ tem sofrido um intenso processo de transformação. A grande heterogeneidade em termos de tamanho e de tipo de empresas predominante nos anos 70 , caracterizada pela convivência de grandes e médias empresas, setorialmente especializadas ou diversificadas, foi substituída nos anos 90 por uma estrutura que se caracteriza por um número reduzido de grandes empresas internacionalizadas e especializadas setorialmente. Por sua vez, a dupla segmentação dos mercados (por espaço nacional/regional e por renda) e o predomínio do caráter nacional/regional da indústria, que limitava a expansão de sua capacidade produtiva aos respectivos mercados na década de 1970, foram sendo gradualmente substituídos pela segmentação dos mercados por renda e pela internacionalização da indústria, através da expansão de sua capacidade produtiva em mercados de países desenvolvidos na década de 1980 e de países emergentes, como o Leste Europeu, o Sudeste Asiático e a América Latina, na década de 1990, principalmente através de aquisições e fusões com produtores locais. Este movimento foi acompanhado por um rearranjo patrimonial da indústria e pela intensificação do processo de reestruturação produtiva e organizacional das principais empresas nos anos $90^{8}$ (quadro 1).

O movimento de concentração e internacionalização tem transformado a estrutura da indústria brasileira de linha branca, ${ }^{9}$ e as estratégias de suas principais empresas têm acompanhado as tendências internacionais. A existência de um número reduzido de grandes empresas familiares nacionais na década de 1970 foi substituída pela predominância de um número ainda menor de grandes empresas sob o controle de grandes conglomerados estrangeiros na década de 1990. A entrada recente de grandes grupos multinacionais tem provocado um acirramento da concorrência, gerando importantes mudanças em sua estrutura. Esta entrada tem se verificado através de aquisições de empresas nacionais e/ou implantação de plantas próprias no país, mas 


\begin{tabular}{|c|c|c|c|c|c|c|c|c|}
\hline \multicolumn{2}{|c|}{ 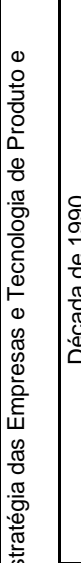 } & 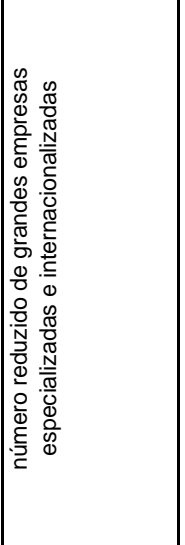 & 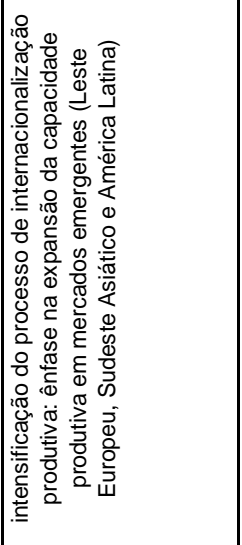 & 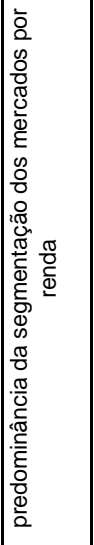 & 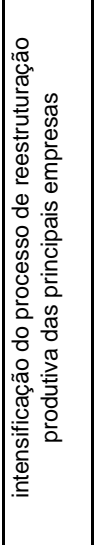 & 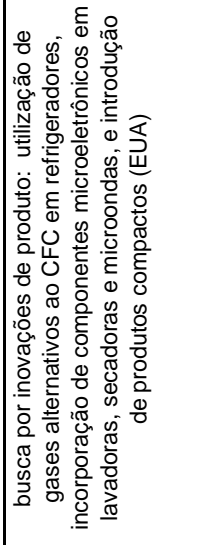 & 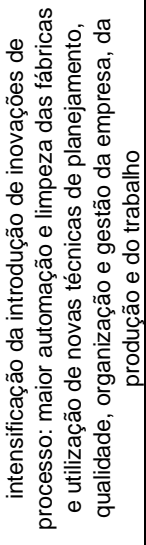 & \\
\hline 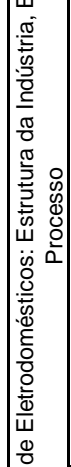 & & 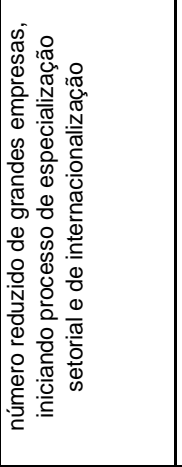 & 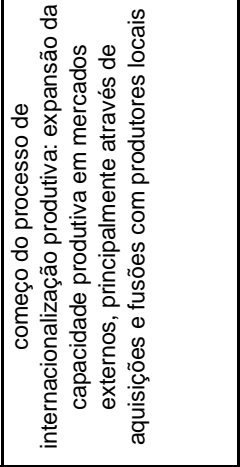 & 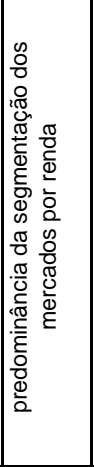 & 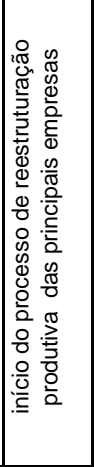 & 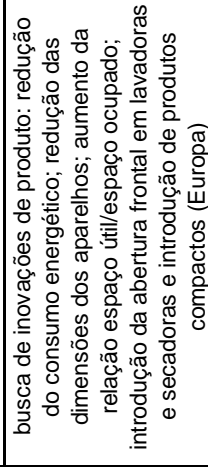 & 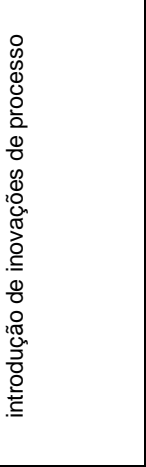 & \\
\hline 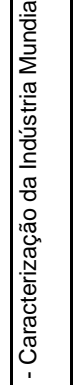 & 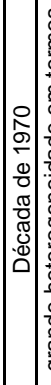 & 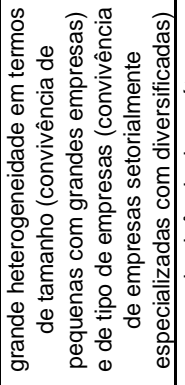 & 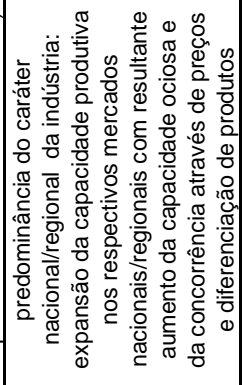 & 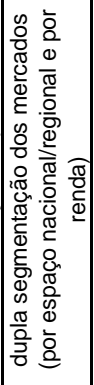 & 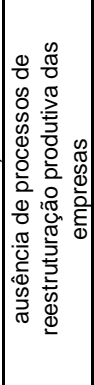 & 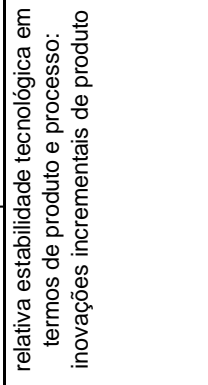 & 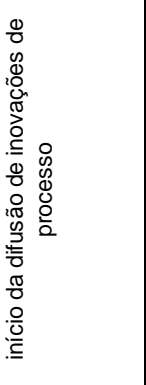 & 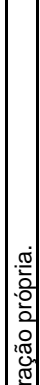 \\
\hline $\begin{array}{l}\frac{0}{\bar{a}} \\
\frac{\pi}{3} \\
\text { वे }\end{array}$ & & 㳯 & \multicolumn{3}{|l|}{ 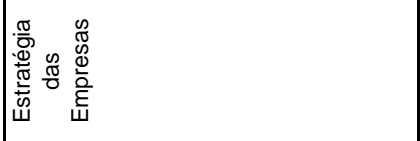 } & \multicolumn{2}{|l|}{ 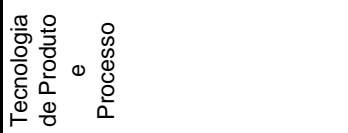 } & 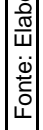 \\
\hline
\end{tabular}




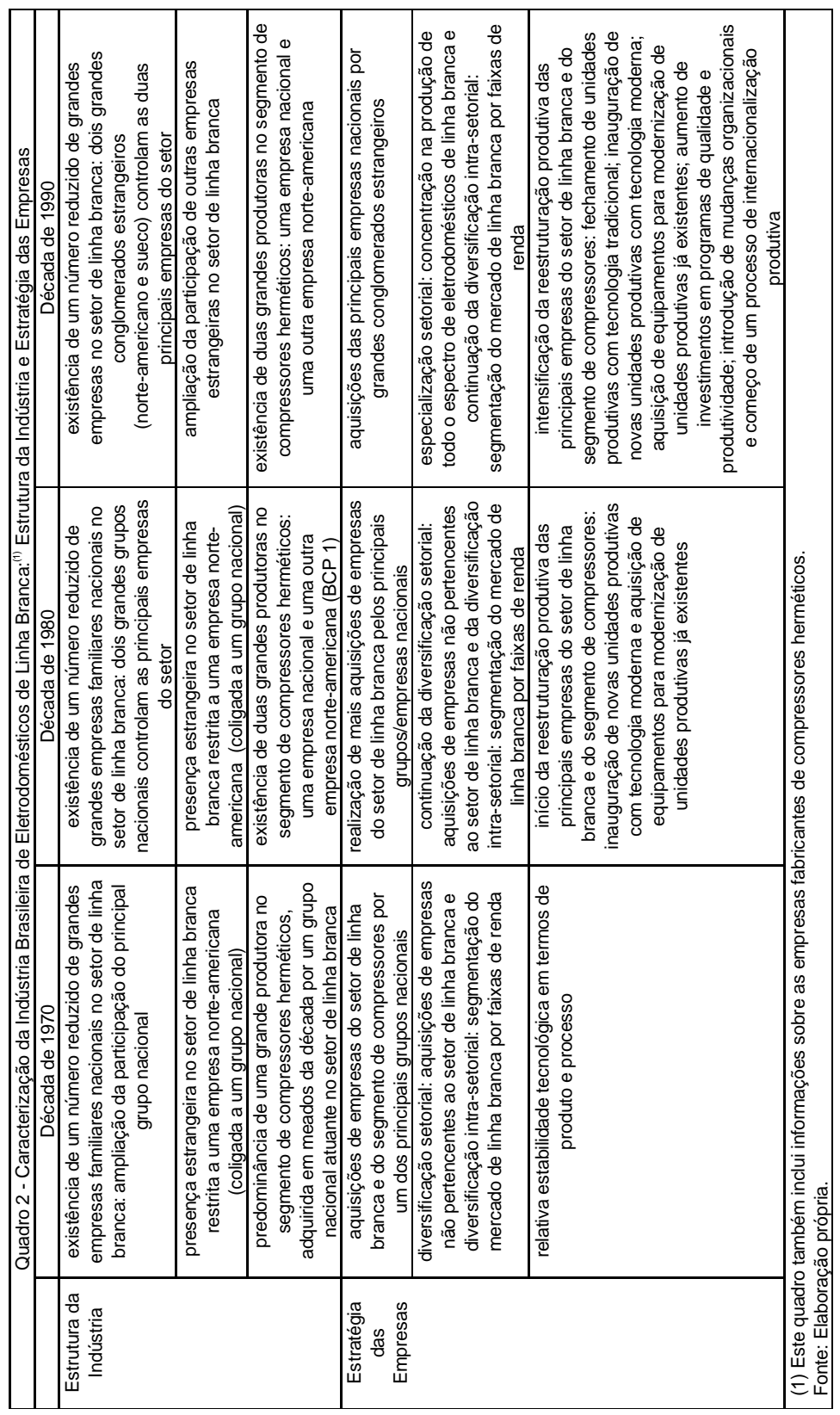


também via exportações a partir de plantas localizadas em outros países (quadro 2). As grandes empresas têm adotado estratégias de especialização setorial, concentrando-se na produção de todo o espectro de eletrodomésticos de linha branca, bem como de diversificação intrasetorial, através da segmentação do mercado por faixas de renda. No que se refere à tecnologia de produto e processo, as empresas têm seguido as tendências internacionais, desenvolvendo estratégias de reestruturação (investindo em equipamentos, programas de qualidade e mudanças organizacionais). ${ }^{10}$

A indústria brasileira de eletrodomésticos (incluindo os portáteis e não-portáteis) apresentou um desempenho muito favorável na primeira metade da década de 1990, com o crescimento das vendas industriais, do faturamento e das exportações, resultante do esforço no sentido de ampliar seu mercado e aumentar a competitividade de seus produtos, destacando-se a elevação da produtividade, que reflete o aumento da produção associado à queda do emprego (Cunha 1997).

\section{Reestruturação produtiva, trabalho e qualificação}

Ao longo dos anos 80, acompanhando as tendências internacionais, a indústria brasileira de linha branca inicia um lento processo de reestruturação. Nessa etapa inicial, caracterizada pela crise econômica, que provocou a retração do mercado interno ao qual se destinava sua produção, a difusão de inovações tecnológicas e organizacionais nas empresas assume um caráter defensivo: poucos investimentos em equipamentos e experiências localizadas de inovações organizacionais. A crise do início dos anos 90, associada ao movimento de abertura do mercado nacional, acarretou a generalização e a intensificação dos processos de reestruturação das empresas do setor. Esta tendência se mantém após a estabilização da economia, agora relacionada com a entrada de empresas estrangeiras no país e ao aumento da concorrência no mercado interno.

Todas as empresas da amostra haviam introduzido ou estavam introduzindo algum tipo de inovação. A enorme pressão por redução de custos, associada ao aumento das exigências relativas à qualidade, aparece como fator-chave para a intensificação da difusão de inovações relativas à gestão da empresa, à organização do trabalho e às relações interfirmas (tabela 2). 


\begin{tabular}{|c|c|c|}
\hline \multicolumn{3}{|c|}{ Tabela 2 - Inovações introduzidas nas empresas ${ }^{(1)}$} \\
\hline Inovações na gestão da empresa & Lista de empresas & № empresas \\
\hline focalização para produtos e/ou clientes & $\begin{array}{c}\mathrm{BCP}, \mathrm{BCP} 1,1.1,1.2,1.3,1.5,1.8 \\
1.9,1.10\end{array}$ & 9 \\
\hline redução dos níveis hierárquicos & BCP, BCP 1 & 2 \\
\hline $\begin{array}{l}\text { mudanças no organograma da empresa visando } \\
\text { integração/horizontalização }\end{array}$ & $\mathrm{BCP}, \mathrm{BCP} 1$ & 2 \\
\hline enxugamento do quadro funcional & $\mathrm{BCP}, \mathrm{BCP} 1,1.3$ & 3 \\
\hline formalização do sistema de qualidade & BCP, BCP $1,1.1$ a 1.10 & 12 \\
\hline certificação pela norma ISO 9000 & $\mathrm{BCP}, \mathrm{BCP} 1,1.4,1.8,1.10$ & 5 \\
\hline exigência de $1^{\circ}$ grau completo no recrutamento & BCP, BCP $1,1.1$ a $1.6,1.9,1.10$ & 10 \\
\hline programas de treinamento & $\mathrm{BCP}, \mathrm{BCP} 1,1.1$ a $1.6,1.8,1.9,1.10$ & 11 \\
\hline programas participativos & $\mathrm{BCP}, \mathrm{BCP} 1,1.2,1.4,1.8,1.9$ & 6 \\
\hline mudanças nas estruturas de cargos e salários & BCP, BCP 1 & 2 \\
\hline programas de participação nos resultados & $\mathrm{BCP}, \mathrm{BCP} 1,1.5,1.8$ & 4 \\
\hline \multicolumn{3}{|l|}{ Inovações na gestão da produção } \\
\hline minifábricas e/ou celularização da produção & $\mathrm{BCP}, \mathrm{BCP} 1.6,1.8$ & 3 \\
\hline utilização de equipamentos flexíveis & BCP $1,1.2$ a $1.6,1.8,1.9,1.10$ & 9 \\
\hline utilização de ferramentas da qualidade & $\mathrm{BCP}, \mathrm{BCP} 1,1.3,1.8$ & 4 \\
\hline JIT/kanban interno & BCP, BCP 1.6 & 2 \\
\hline JIT/kanban externo & BCP $1,1.1,1.2,1.3,1.4,1.6,1.8$ & 7 \\
\hline \multicolumn{3}{|l|}{$\begin{array}{ll}\text { Inovações na organização do trabalho } \\
\end{array}$} \\
\hline $\begin{array}{l}\text { redefinição dos postos de trabalho no sentido da } \\
\text { polivalência }\end{array}$ & $\mathrm{BCP}, \mathrm{BCP} 1,1.5,1.7$ & 4 \\
\hline trabalho em grupo & BCP & 1 \\
\hline $\begin{array}{l}\text { transferência de atividades de qualidade para } \\
\text { pessoal da produção }\end{array}$ & $\begin{array}{c}\text { BCP, BCP } 1, \begin{array}{c}1.1,1.2,1.3,1.5,1.6 \\
1.7,1.9\end{array}\end{array}$ & 9 \\
\hline $\begin{array}{l}\text { transferência de atividades de manutenção para } \\
\text { pessoal da produção }\end{array}$ & $\mathrm{BCP} 1,1.1$ a 1.10 & 11 \\
\hline \multicolumn{3}{|l|}{ Inovações nas relações interfirmas } \\
\hline $\begin{array}{l}\text { programas de avaliação, desenvolvimento e } \\
\text { qualificação de fornecedores (implantação e/ou } \\
\text { participação) }\end{array}$ & $\mathrm{BCP}, \mathrm{BCP} 1,1.1$ a 1.10 & 12 \\
\hline $\begin{array}{l}\text { externalização de atividades produtivas pelas } \\
\text { empresas }\end{array}$ & $\mathrm{BCP}, \mathrm{BCP} 1,1.2,1.3,1.8$ & 5 \\
\hline $\begin{array}{l}\text { externalização de atividades produtivas para as } \\
\text { empresas }\end{array}$ & BCP $1.1,1.2,1.3,1.6$ a 1.10 & 8 \\
\hline $\begin{array}{l}\text { externalização de atividades auxiliares pelas } \\
\text { empresas }^{(4)}\end{array}$ & BCP, ВCP $1,1.5,1.9$ & 4 \\
\hline \multicolumn{3}{|c|}{$\begin{array}{l}\text { (1) As respostas não são exclusivas. Portanto, o número de respostas pode superar o número de } 12 \\
\text { empresas que responderam à questão. } \\
\text { (2) Por exemplo, inspeção visual, realização de medições e/ou autocontrole. } \\
\text { (3) Por exemplo, verificação de algum requisito como parte de um programa de manutenção de máquinas e } \\
\text { equipamentos, lubrificação e troca de óleo, limpeza periódica de máquinas etc. } \\
\text { (4) As atividades auxiliares externalizadas pelas empresas da amostra podem compreender restaurante, } \\
\text { limpeza, vigilância/segurança, transporte de funcionários e de carga, assistência médica e odontológica, } \\
\text { recrutamento/seleção etc. } \\
\text { Fonte: Pesquisa de Campo (1996-1997). }\end{array}$} \\
\hline
\end{tabular}

As pressões por implantação e/ou formalização do sistema de qualidade, visando, quase sempre, a certificação pelas normas da série ISO 9000 , têm provocado e orientado a difusão em cascata, nessa cadeia produtiva, de inovações associadas ao modelo de especialização flexível (Piore \& Sabel 1984), modificando sua estrutura e forma de organização. Este processo afeta a estrutura das empresas (níveis hierárquicos, 
estrutura organizacional, sistemas de autoridade e controle), a organização do processo de trabalho, as políticas de gestão de recursos humanos (cargos e salários, treinamento, utilização de programas participativos) e as relações interfirmas (relações horizontais e verticais entre as empresas). ${ }^{11}$

No que se refere às inovações na organização e na gestão da produção e do trabalho, pode-se observar a utilização de: a) equipamentos flexíveis, especialmente os de comando numérico; b) ferramentas da qualidade, como o controle estatístico de processo; c) novos sistemas/técnicas de planejamento e controle da produção (PCP), como o just-intime/kanban; ${ }^{12}$ d) a redefinição dos postos de trabalho no sentido da polivalência; e e) a transferência de atividades de qualidade e de manutenção para o pessoal da produção direta.

Entre as mudanças nas relações interfirmas, destacam-se o movimento de externalização/internalização ${ }^{13}$ de atividades produtivas e a implantação e/ou a participação em programas de avaliação e desenvolvimento de fornecedores, cujo objetivo é a redução do número de fornecedores. As empresas contratantes têm tratado de seguir uma estratégia de redução do número de fornecedores, fortemente baseada em critérios relativos ao desempenho em qualidade (ainda que o preço mantenha uma grande importância) e, em alguns casos, mantendo somente um fornecedor para alguns produtos ou serviços.

Dessa forma, o processo de reestruturação em empresas clientes induz a introdução de inovações em seus pequenos e médios fornecedores, especialmente através dos programas de avaliação e de desenvolvimento de fornecedores. Essas empresas, pressionadas para reduzir custos, implantar procedimentos de qualidade e aumentar sua flexibilidade no atendimento aos clientes, passam também a se reestruturar.

\section{Relações interfirmas}

Uma das conseqüências do processo de reestruturação é a mudança nas relações entre clientes e fornecedores (relações verticais). A pesquisa permite identificar algumas tendências na reorganização dessas relações ao longo da cadeia produtiva analisada:

- a intensificação do movimento de externalização/internalização de atividades (auxiliares e produtivas) em todos os níveis da cadeia, o que implica a redefinição da divisão do trabalho entre empresas; 
- a enorme pressão dos clientes no sentido da formalização do sistema de qualidade de seus fornecedores, que se traduz em avaliações e auditorias periódicas e, mais recentemente, na exigência de certificação pelas normas da série ISO 9000;

- a crescente exigência de flexibilidade, ou seja, de capacidade de atender prontamente às freqüentes mudanças na programação dos pedidos de seus clientes.

A primeira tendência geral observada na reorganização das relações entre clientes e fornecedores é o movimento de externalização/ internalização de atividades com a conseqüente redefinição da divisão do trabalho entre empresas. Esse movimento é extremamente complexo, heterogêneo e dinâmico, apresentando características de ensaio e erro. Ele se inicia como resultado do processo de reestruturação das grandes empresas, no qual focalização, flexibilização e redução de custos aparecem fortemente associados ao movimento pela qualidade, provocando efeitos em cascata ao longo da cadeia. A externalização/internalização de atividades produtivas e auxiliares (restaurante, vigilância, transporte, limpeza etc.) é um fenômeno generalizado, afetando não somente grandes, como também pequenas e médias empresas (tabela 2).

Algumas variáveis parecem ser especialmente importantes na definição do que e do para quem se externalizam as atividades produtivas.

O tipo de produto e/ou processo envolvido na externalização é uma variável-chave para a definição do que se externaliza, e considerações sobre redução de custos são essenciais para a decisão. Assim, cabe destacar, por um lado, a externalização de processos intensivos em trabalho, cuja localização fora da empresa não afeta o fluxo produtivo (como, por exemplo, tarefas de montagem e usinagem de peças simples) e, por outro, a de produtos e/ou processos mais complexos, que dependem de fornecedores especializados. Nesse caso, a disponibilidade de um tecido industrial suficientemente eficiente e confiável, na região onde está localizada a empresa, é decisiva para viabilizar este tipo de externalização, cujo objetivo é também a redução de custos através da diminuição do grau de verticalização.

Por sua vez, a definição do para quem se externalizam as atividades produtivas depende de variáveis relativas à natureza e à intensidade das relações cliente-fornecedor: (a) o histórico da relação entre o cliente e o fornecedor, ou seja, a experiência passada, que determina graus de confiabilidade recíproca; (b) o peso do cliente para o fornece- 
dor e vice-versa; e (c) a combinação porte (tamanho e capacidade de investimento) e competência (capacidade técnica) das empresas clientes e fornecedoras.

Outra tendência geral identificada na reorganização das relações verticais é a enorme pressão dos clientes, sobre seus fornecedores, por formalização da qualidade e redução de custos. Essa exigência se traduz em avaliações e auditorias periódicas por parte das empresas clientes e, crescentemente, em pressões para a obtenção de certificação pelas normas da série ISO $9000^{14}$. Esse tipo de avaliação orienta a escoIha dos fornecedores que serão mantidos ou eliminados pelas políticas de redução do número de fornecedores.

Esse processo pode ser claramente detectado nas empresas estudadas, para as quais, inicialmente, o controle da qualidade dos produtos fornecidos é medido pelos índices de rejeição no cliente (além do preço e/ou do prazo de entrega), seguido por visitas do cliente ao fornecedor para autorizar o fornecimento com "qualidade assegurada", o que leva à eliminação do controle de entrada na empresa cliente. A "qualidade assegurada" é geralmente seguida pela realização de avaliações periódicas, envolvendo mais informações e uma maior freqüência de visitas para a classificação dos fornecedores. Posteriormente, as empresas clientes passam a exigir a certificação pelas normas ISO 9000, o que, em tese, elimina a necessidade de o cliente auditar seus fornecedores, já que a empresa certificadora realiza auditorias periódicas. Entre os fornecedores de primeira e segunda linhas da amostra, 5 empresas já estavam certificadas pelas normas ISO 9000, 5 forneciam com qualidade assegurada para algum cliente, 9 eram auditadas periodicamente pelos clientes e somente 2 eram avaliadas apenas por seu desempenho no cliente.

As estratégias de redução do número de fornecedores (baseadas em critérios relativos ao desempenho em qualidade, preço e prazos de entrega) estão orientadas pela idéia de estabelecer um tipo de relação mais cooperativa com alguns fornecedores selecionados. Essa cooperação pode assumir diferentes formas: a) apoio às empresas subcontratadas no desenvolvimento de melhores tecnologias de produção; b) sugestões para as empresas subcontratadas melhorarem seus sistemas de qualidade; $c$ ) envolvimento do fornecedor no processo de desenvolvimento de novos produtos/processos; e d) estabelecimento de acordos de compras de maior duração.

Todos os fornecedores de segunda linha afirmaram receber algum tipo de apoio formal e/ou informal de pelo menos um de seus clientes para 
implantação de seus sistemas de qualidade. Ademais, várias empresas mencionaram outras formas de apoio, sendo a mais freqüente o treinamento para qualidade, incluindo estágios de funcionários em empresas clientes, além de palestras e/ou cursos sobre qualidade por eles oferecidos. Outras formas mencionadas foram: uso de laboratório do cliente, apoio para redução de custos e para organização da produção, transporte de partes e produtos, a compra conjunta de insumos e o pagamento adiantado. No entanto, essas empresas também afirmam que a assistência em qualidade oferecida pelos programas de desenvolvimento de fornecedores das empresas clientes não corresponde ao nível das exigências, ou seja, existem demasiadas exigências e pouca assistência efetiva.

A terceira tendência observada na reorganização das relações entre clientes e fornecedores é a crescente exigência de flexibilidade, isto é, o pronto atendimento às mudanças freqüentes na programação dos clientes (cancelamentos, adiamentos ou aumentos repentinos de pedidos, decorrentes da instabilidade dos mercados). Os fornecedores necessitam estar preparados para mudanças repentinas na programação de sua produção, exigência que tem induzido a implantação de sistemas just-in-time/kanban (encontrados em 7 empresas da amostra, todos fornecedores diretos).

Assim, os clientes parecem se interessar apenas em manter fornecedores que possam oferecer produtos com qualidade a preços reduzidos com flexibilidade suficiente para atender a variações de demanda decorrentes da instabilidade presente nos mercados finais. Isto tem mudado a natureza dos acordos, que passam a envolver uma programação referente a metas a serem atingidas nessas três dimensões.

\section{Trabalho, qualificação e relação com os sindicatos de trabalhadores}

Este conjunto de mudanças gera dois tipos de movimento, afetando a estrutura do emprego e a hierarquização das qualificações:

- mudanças na divisão e no conteúdo do trabalho no interior das empresas, redefinindo o perfil de qualificação do trabalhador e elevando a produtividade, provocando a redução do volume do emprego;

- mudanças na divisão do trabalho entre empresas e consequente reorganização da estrutura do emprego na cadeia produtiva. 
As pressões por redução de custos, qualidade e flexibilidade intensificam a reestruturação das empresas em todos os níveis da cadeia estudada, induzindo inovações na organização da produção e do trabaIho e nas políticas de gestão (tabela 2).

O movimento de reorganização da produção e do trabalho nas empresas caracteriza-se pela introdução de diversos tipos de inovação: a) aumento dos investimentos em automação dos processos de produção, principalmente através da aquisição de novos equipamentos mais flexíveis; b) mudanças no lay out das plantas, com a implantação das minifábricas e das células de produção; c) mudanças nos postos de trabalho, com ênfase na polivalência; e d) adoção de novas técnicas de planejamento e controle da produção e da qualidade com vistas à obtenção de certificação pelas normas ISO 9000 (jit/kanban, CEP). Essas inovações, por sua vez, trazem consigo uma redefinição na divisão e no conteúdo do trabalho, através da ampliação das atribuições do trabalhador da produção, para o qual são transferidas atividades relacionadas à formalização da qualidade e à manutenção.

Este conjunto de mudanças implica a construção de um novo perfil de trabalhador com mais escolaridade, capacidade de trabalhar em grupo e maior comprometimento com os objetivos da empresa, o chamado trabalhador multifuncional, induzindo mudanças nas políticas de gestão de recursos humanos. Dessa forma, observa-se a elevação dos requisitos de escolaridade como critério de seleção e recrutamento (primeiro grau completo), a organização de programas de treinamento, a introdução de programas participativos, a introdução de novas estruturas de cargos e salários e de programas de participação nos resultados (tabela 2).

Como observam Gitahy e Bresciani (1997), a organização da produção e do trabalho adquiriu uma nova lógica, que incorpora mecanismos de autocontrole capazes de viabilizar a redução dos níveis hierárquicos (diminuindo o número de chefes) e de aumentar a autonomia dos trabalhadores no que diz respeito à condução dos processos produtivos. Seu êxito depende da motivação e da adesão dos participantes às metas de competitividade da empresa e dos programas de qualidade, e às novas rotinas implementadas. É nesse contexto que surge não só a necessidade dos programas de treinamento, como a de adoção de diferentes tipos de programas participativos, visando motivar e/ou envolver o conjunto dos funcionários, como a difusão de informações sobre o desempenho da empresa, os prêmios por idéias através da existência de 
planos de sugestões, a introdução de carreiras multifuncionais e de programas de participação nos resultados.

A implantação de programas de qualidade e de novas formas de gestão do trabalho tem sido acompanhada por programas de treinamento (tabela 3), organizados não só pelas empresas, mas também por vários tipos de instituição. Os cursos organizados por escolas técnicas e/ou por centros profissionalizantes constituem parte importante da formação dos trabalhadores industriais, assim como os cursos organizados em convênio com diferentes escolas (de primeiro e segundo graus, universidades, de idiomas). Vale destacar o papel das universidades na reciclagem dos profissionais, principalmente de técnicos e gerentes que, freqüentemente, realizam cursos de pós-graduação ou de extensão universitária.

\begin{tabular}{|l|c|c|}
\hline \multicolumn{1}{|c|}{ Tabela 3: Programas de treinamento oferecidos aos funcionários pelas empresas da amostra(1) } \\
\hline \multicolumn{1}{|c|}{ pela empresa } & Lista de empresas & No. empresas \\
\hline \multicolumn{1}{|c|}{ pela empresa com apoio de outras instituições } & BCP , BCP 1, 1.5, 1.8, 1.9,1.10 & 6 \\
\hline $\begin{array}{l}\text { por escolas técnicas e/ou por centros } \\
\text { profissionalizantes (SENAl, etc.) }\end{array}$ & BCP $1,1.4$ & 2 \\
\hline $\begin{array}{l}\text { em convênio com escolas e/ou outras instituições } 1,1.4,1.9 \\
\text { educacionais }\end{array}$ & BCP, BCP 1, 1.1, 1.4 & 4 \\
\hline por universidades & BCP, BCP 1.1, 1.6, 1.10 & 3 \\
\hline por outras empresas (clientes ou fornecedores) & BCP 1.1, 1.2, 1.3, 1.5, 1.9, 1.10 & 6 \\
\hline $\begin{array}{l}\text { por sindicatos, associações classistas e/ou } \\
\text { consultorias }\end{array}$ & BCP 1, BCP 1.6, 1.9 & 3 \\
\hline $\begin{array}{l}\text { por iniciativa dos funcionários, pagos } \\
\text { total/parcialmente pela empresa }\end{array}$ & BCP, BCP 1, BCP 1.6, 1.8 & 4 \\
\hline $\begin{array}{l}\text { por iniciativa dos funcionários, não sendo pagos } \\
\text { pela empresa }\end{array}$ & BCP 1.1, 1.10 & 2 \\
\hline não há treinamento & BCP 1.7 & 1 \\
\hline $\begin{array}{l}\text { (1) As respostas não são exclusivas. } \\
\text { Fonte: Pesquisa de Campo (1996-1997). }\end{array}$ & \\
\hline
\end{tabular}

O conteúdo dos cursos oferecidos pelas diversas instituições é bastante variado, predominando os relacionados ao sistema e a ferramentas de qualidade, técnicos/operacionais e comportamentais, voltados para a motivação, para a qualidade e a produtividade. Cabe também destacar os cursos supletivos de primeiro e segundo graus, os de idiomas e até um curso de teatro organizado por uma das empresas para seus engenheiros, com o objetivo de estimular o potencial criativo dos funcionários (tabela 4).

A reorganização do trabalho no interior das empresas, associada a novos critérios de seleção e recrutamento, tem se traduzido em mudanças na composição da mão-de-obra das empresas, com o predomínio de uma mão-de-obra mais escolarizada ( 9 empresas da amostra já possuíam mais 


\begin{tabular}{|c|c|c|}
\hline Tipos de curso & Lista de empresas & No. empresas \\
\hline MBA & $\mathrm{BCP}^{(5)}$ & 1 \\
\hline supletivos de primeiro e segundo grau & $\mathrm{BCP}, \mathrm{BCP} 1, \mathrm{BCP} 1.1,1.4$ & 4 \\
\hline matemática básica e/ou avançada & BCP $1.5,1.9$ & 2 \\
\hline segurança no trabalho & BCP 1 & 1 \\
\hline cursos técnicos/operacionais ${ }^{(2)}$ & $\begin{array}{c}\text { BCP, BCP 1, ВCP 1.3, 1.4, } \\
1.5,1.9,1.10\end{array}$ & 7 \\
\hline $\begin{array}{l}\text { uso e/ou manutenção de equipamentos } \\
\text { e/ou instrumentos }{ }^{(3)}\end{array}$ & ВCP $1.4,1.5,1.9,1.10$ & 4 \\
\hline kanban & BCP 1.6 & 1 \\
\hline programa $5 S$ & BCP 1.6 & 1 \\
\hline $\begin{array}{l}\text { cursos relacionados ao sistema e a } \\
\text { ferramentas de qualidade }{ }^{(4)}\end{array}$ & $\begin{array}{c}\mathrm{BCP}, \mathrm{BCP} 1,1.1,1.4,1.8 \\
1.9,1.10\end{array}$ & 7 \\
\hline $\begin{array}{l}\text { motivação para a qualidade e produtividade } \\
\text { (cursos e/ou palestras comportamentais) }\end{array}$ & $\begin{array}{c}\mathrm{BCP}, \mathrm{BCP} 1, \mathrm{BCP} 1.2,1.4, \\
1.6,1.9\end{array}$ & 6 \\
\hline teatro & $\mathrm{BCP}^{(6)}$ & 1 \\
\hline idiomas & $\mathrm{BCP}, \mathrm{BCP} 1,1.4,1.8$ & 4 \\
\hline não há cursos & BCP 1.7 & 1 \\
\hline \multicolumn{3}{|c|}{$\begin{array}{l}\text { (1) As respostas não são exclusivas } \\
\text { (2) Como cursos de controle de medidas, desenho, metrologia, comando numérico, tratamento térmico, etc } \\
\text { (3) Cursos para pessoal específico de manutenção e/ou operadores de máquinas. } \\
\text { (4) Como cursos de CEP, ISO 9000, etc. } \\
\text { (5) Os gerentes da empresa frequentam cursos de mestrado na PUC de Curitiba. } \\
\text { (6) A empresa organiza cursos de teatro para engenheiros com o objetivo de estimular a criatividade. } \\
\text { Fonte: Pesquisa de Campo (1996-1997). }\end{array}$} \\
\hline
\end{tabular}

de $50 \%$ de seus funcionários com primeiro grau completo e, em 4 delas, essa proporção já havia ultrapassado os $70 \%$ ) e mais jovem (menos de 30 anos na maioria das empresas). Um dos entrevistados afirmou que pessoas mais novas "têm maior disposição e vontade de crescer e mais jogo de cintura"; e outro, que as pessoas idosas geralmente não conseguem se adaptar à nova filosofia das empresas. No entanto, aparecem algumas exceções relacionadas à natureza do trabalho. Segundo outro entrevistado, "na ferramentaria, por exemplo, procura-se ter mão-de-obra com mais experiência, com 40 a 45 anos", embora prefira-se pessoas com mais ou menos 30 anos para trabalhar com máquinas de controle numérico.

No que se refere à composição da mão-de-obra por gênero, observa-se uma maior presença de mulheres na produção em empresas que realizam atividades de montagem. Ainda que a maioria das ocupações da indústria metalmecânica sejam tradicionalmente masculinas (quatro empresas não utilizam mulheres na produção), entre as nove empresas que forneceram informações sobre gênero, uma tem menos de $10 \%$ de mulheres; três, de $11 \%$ a $30 \%$ e duas, mais de $30 \%$, uma delas com mais de $80 \%$ (montagem de componentes eletroeletrônicos).

No entanto, segundo alguns entrevistados, existe uma tendência de ampliação do uso de mulheres na produção. Um deles afirmou que, em sua 
empresa, cada célula de produção deve ter a presença de pelo menos duas mulheres para diversificar a formação das equipes. Para ele, "a sociedade precisa entender que a fábrica não é lugar sujo, não é ambiente só para homens. [...] A mão-de-obra feminina e masculina se equivalem, pois existem pontos negativos e positivos em ambos. As mulheres têm um nível de absenteísmo maior, porém a produtividade é maior, o que acaba compensando. Na minha minifábrica, valoriza-se, sem divulgar, a contratação de casais, mas em células separadas". Outro entrevistado afirmou que "a mão-de-obra feminina é mais estável, mesmo as mulheres mais jovens. A rotatividade e o absenteísmo são menores". E um terceiro destacou que as mulheres "são mais atentas" e rendem mais em certas situações.

No que se refere ao volume do emprego, a tendência é de redução do emprego associada à elevação do faturamento (acompanhando as tendências gerais da indústria de eletrodomésticos).${ }^{15} \mathrm{~A}$ articulação entre as pressões por redução de custos, formalização da qualidade, elevação da produtividade e flexibilidade nas entregas provoca transformações significativas na divisão do trabalho, tanto dentro das empresas (pela reorganização do processo de trabalho, associando investimentos em equipamentos e inovações organizacionais), como entre as empresas (movimento de internalização/externalização de atividades).

Este movimento se reflete na distribuição do emprego entre os diversos tipos de empresa e nas condições de trabalho, provocando os mais diversos tipos de arranjos e experiências. ${ }^{16} \mathrm{~A}$ externalização de atividades de montagem, por exemplo, implica a criação de pequenas empresas localizadas perto da planta de seus grandes clientes, pagando salários mais baixos e com poucos benefícios sociais. A diferença salarial entre os grandes clientes e seus fornecedores mais especializados não é significativa, mas os benefícios vão depender do porte da empresa.

Este processo tem importantes conseqüências não só para a estrutura do emprego, como para o perfil da mão-de-obra, induzindo mudanças na estrutura e hierarquização das qualificações. Se, por um lado, a elevação da produtividade está associada à introdução de inovações tecnológicas e organizacionais, por outro, estas inovações têm implicado a intensificação do trabalho e maiores exigências de escolaridade, num contexto em que o mercado de trabalho é extremamente desfavorável aos trabalhadores.

A busca de um maior comprometimento da mão-de-obra tem levado a mudanças importantes na gestão de recursos humanos, num con- 
texto marcado pela baixa presença dos sindicatos de trabalhadores nas empresas (tabela 5). A sindicalização parece ser significativa (ainda que baixa) apenas nas grandes empresas, enquanto nas pequenas e médias parece ser baixa ou inexistente. Os proprietários e/ou gerentes da maioria das empresas consideram as relações com o sindicato boas, na medida em que este não interfere na vida de suas empresas. Alguns comentários de entrevistados das empresas menores merecem ser mencionados por deixarem transparecer as opiniões existentes nas empresas sobre a atuação dos sindicatos de trabalhadores. Um dos entrevistados acredita que o sindicato deixou de despertar o interesse dos funcionários pela busca de seus direitos, "garantindo benefícios que ele não foi obrigado a buscar por conta própria". Atualmente, ele acredita que os trabalhadores estão tendo que lutar mais pelos seus direitos por si mesmos. Outro mencionou sentir a existência de restrições do sindicato quanto à polivalência dos trabalhadores, apesar de declarar que este exerce pouca influência na empresa e que a maior parte dos funcionários não é sindicalizada. $E$ um terceiro afirmou que "a grande maioria [dos trabalhadores] só usa o sindicato como clube de férias".

\begin{tabular}{|c|c|c|c|}
\hline \multicolumn{4}{|c|}{ Tabela 5: relação das empresas com o sindicato de trabalhadores } \\
\hline Sindicatos & Eixo das reivindicações & Lista de empresas & No. empresas \\
\hline $\begin{array}{c}\text { Metalúrgicos de São } \\
\text { Carlos (Força Sindical) }\end{array}$ & $\begin{array}{c}\text { salário, estabilidade, redução } \\
\text { da jornada de trabalho para 40 } \\
\text { horas, cesta básica }\end{array}$ & $\begin{array}{c}\text { BCP, BCP1, } \\
\text { BCP1.1, BCP1.2 }\end{array}$ & 4 \\
\hline $\begin{array}{c}\text { Metalúrgicos de Campinas } \\
\text { (CUT) }\end{array}$ & $\begin{array}{c}\text { salário, abono, 40 horas } \\
\text { semanais e unificação das } \\
\text { datas-base }\end{array}$ & $\begin{array}{c}\text { BCP1.3, BCP1.7, } \\
\text { BCP1.8 }\end{array}$ & 3 \\
\hline $\begin{array}{c}\text { Metalúrgicos de Limeira, } \\
\text { (CUT) }\end{array}$ & participação nos resultados & BCP1.5, BCP1.6 & 2 \\
\hline $\begin{array}{c}\text { Metalúrgicos de Piracicaba } \\
\text { Químicos e Farmacêuticos }\end{array}$ & $\begin{array}{c}\text { salário e redução da jornada } \\
\text { salarial, aumentoposção }\end{array}$ & BCP1.9 & 1 \\
\hline \multicolumn{2}{|c|}{ nd } & BCP1.10 & 1 \\
\hline não sabe & BCP1.4 & 1 \\
\hline
\end{tabular}

Esta falta, não somente da presença, mas mesmo de visibilidade dos sindicatos de trabalhadores da região, ${ }^{17}$ indica uma muito baixa (e mesmo nenhuma) participação destas instituições no processo de negociação das inovações que estão sendo introduzidas, seja como negociadores ou como formadores de opinião. Ainda que a conjuntura de desemprego, associada a tendências mais gerais de atomização da ação coletiva, dificulte sua atuação, os temas apontados como eixo de reivindicações parecem estar aquém dos desafios colocados pelo processo de reestruturação produtiva, o que é preocupante, na medida em que a possibilidade de internalizar possíveis 
benefícios sociais dos processos de transformação depende da existência de formas democráticas de negociação das mudanças.

\section{Reconfigurando as relações institucionais}

O processo de reestruturação intensifica duas tendências já observadas neste trabalho: por um lado, a externalização/internalização de atividades associadas a processos de focalização e, por outro, a redução do número de fornecedores, associada a enormes pressões por formalização da qualidade, flexibilidade e redução de custos. Para sobreviver neste ambiente, as empresas têm investido fortemente não só em máquinas e equipamentos, como em programas de qualidade e de retreinamento de seus trabalhadores. Este quadro tem aumentado o relacionamento das empresas com diferentes instituições localizadas na região, para ampliar suas possibilidades de acesso a recursos e a conhecimentos que não podem ser produzidos internamente. Assim, as empresas têm buscado participar e se relacionar com diversos tipos de instituições para mobilizar recursos financeiros, ter acesso a informações recentes e resolver problemas urgentes, mas também porque este relacionamento/ participação é primordial para a difusão de conhecimentos sobre formas adequadas de organização e para a subsequente legitimação e institucionalização das novas práticas. Os sindicatos e as associações patronais, as empresas de consultoria, o sistema de formação profissional, as es-

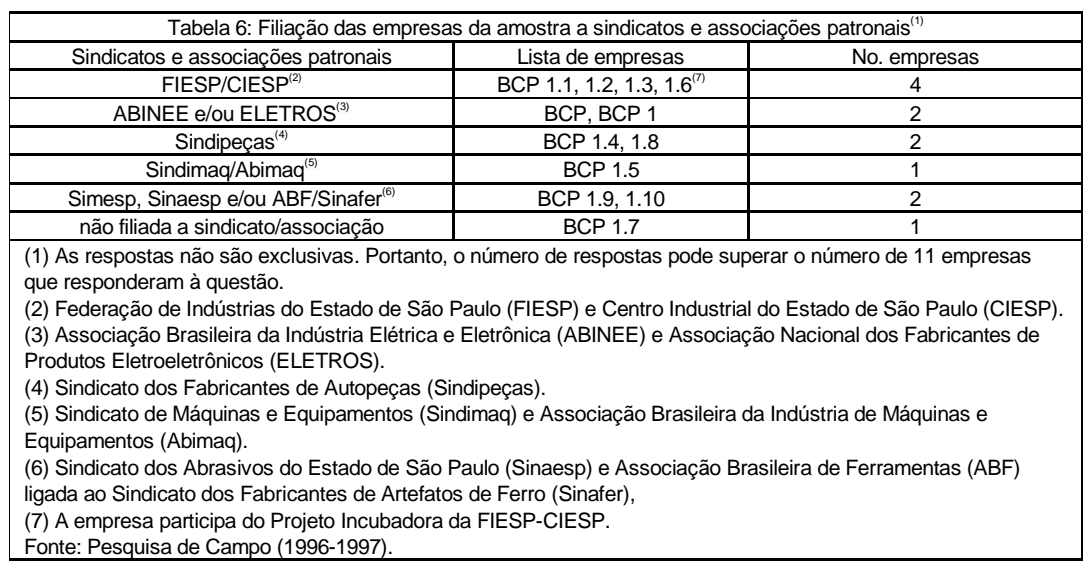


colas técnicas, as universidades e os órgãos de financiamento são exemplos de instituições que exercem um papel fundamental de ligações no que se pode denominar redes de comunicação.

No que se refere às relações horizontais, a maioria das empresas da amostra participa de alguma associação/sindicato patronal, revelando a existência de cooperação, mesmo limitada, entre empresas do mesmo ramo (tabela 6). No entanto, é importante obervar que algumas empresas reclamam do papel muito limitado reservado a pequenas e médias empresas dentro desse tipo de instituição.

É interessante observar a participação de empresas em diversos tipos de associações e/ou fundações de iniciativa empresarial com diferentes objetivos, tais como o Grupo Regional de Recursos Humanos, para a discussão de questões sobre segurança de trabalho e assistência social, e o Programa Regional de Qualidade da Fundação Limeira, cujo objetivo é proporcionar treinamento em qualidade aos funcionários de pequenas e médias empresas, embora contando com a participação eventual de alguns funcionários de grandes empresas ${ }^{18}$ (tabela 7). Vale destacar que uma pequena empresa estava participando do Projeto Incubadora organizado pela Fiesp/Ciesp com a ajuda de outras instituições patronais, governamentais e de ensino. O Projeto Incubadora, incluindo a formação dos primeiros Núcleos de Desenvolvimento Empresarial (incubadoras), nasceu como uma iniciativa da Fiesp/Ciesp, particularmente motivada pelas altas taxas de mortalidade das pequenas empresas nos primeiros anos de sua existência. ${ }^{19}$ Os objetivos do projeto são: a

\begin{tabular}{|c|c|c|}
\hline \multicolumn{3}{|c|}{ Tabela 7: Relações das empresas da amostra com instituições de apoio ${ }^{(1)}$} \\
\hline Instituições & Lista de empresas & No. empresas \\
\hline Senai & $\begin{array}{c}\mathrm{BCP}, \mathrm{BCP} 1,1.1,1.3,1.4,1.5,1.8 \\
1.9,1.10\end{array}$ & 9 \\
\hline Sesi & BCP 1.10 & 1 \\
\hline escolas técnicas & BCP 1.3, 1.4, 1.7 & 3 \\
\hline supletivos $^{(2)}$ & $\mathrm{BCP} 1$ & 1 \\
\hline universidades & $\mathrm{BCP}, \mathrm{BCP} 1,1.1,1.3,1.5,1.10$ & 6 \\
\hline consultorias & BCP 1, BCP 1.3, 1.8, 1.10 & 4 \\
\hline outras empresas & $\mathrm{BCP}, \mathrm{BCP} 1, \mathrm{BCP} 1.5^{(5)}, 1.7$ & 4 \\
\hline órgãos de financiamento ${ }^{(3)}$ & $\mathrm{BCP}, \mathrm{BCP} 1.3$ & 2 \\
\hline fundações/associações $^{(4)}$ & BCP 1, BCP 1.5 & 2 \\
\hline \multicolumn{3}{|c|}{$\begin{array}{l}\text { (1) As respostas não são exclusivas. Portanto, o número de respostas pode superar o número de } 12 \text { empresas que } \\
\text { responderam à questão. } \\
\text { (2) A categoria se refere a diversos tipos de instituições públicas e/ou privadas que oferecem programas supletivos. } \\
\text { (3) Por exemplo, FINEP (Financiadora de Estudos e Projetos), BIRD (Banco Mundial) e FINAME (Financiadora de } \\
\text { Máquinas e Equipamentos). } \\
\text { (4) Por exemplo, Fundação Limeira (Programa Regional de Qualidade) e Grupo Regional de Recursos Humanos, que } \\
\text { discute questões sobre segurança do trabalho e assistência social. } \\
\text { (5) A empresa é representante brasileira de } 3 \text { firmas estrangeiras (Espanha, EUA e Alemanha). } \\
\text { Fonte: Pesquisa de Campo (1996-1997). }\end{array}$} \\
\hline
\end{tabular}


ampliação das chances de sucesso de empresas privadas nascentes, a geração de novos empregos e o fortalecimento da economia local.

O processo de implantação de um núcleo inicia-se a partir do interesse da prefeitura pelo projeto. O Ciesp é responsável pela solicitação de implantação da incubadora junto à Fiesp, a partir da disposição da prefeitura em ceder uma área para sua instalação (condição para a existência do núcleo). O tempo de incubação das novas empresas é de um ano, renovável por igual período; o auxílio oferecido é contínuo, pois as ex-incubadas continuam recebendo assessoria indefinidamente, mesmo estando fora da incubadora: elas têm direito a treinamento, a participação em cursos e a acompanhamento de consultorias.

A participação das prefeituras se restringe à concessão de um espaço para a instalação dos núcleos e a participação da Fiesp/Ciesp engloba todo o apoio administrativo, tecnológico e mercadológico, através do fornecimento de assessoria/consultoria individual e treinamento/cursos individuais e coletivos (o empresário pode utilizar até 400 horas de treinamento anual). A federação tem uma programação de cursos destinada à formação dos empresários, mas pode atender a suas necessidades específicas identificadas juntamente com os coordenadores dos núcleos. Alguns temas são explorados nos treinamentos coletivos: marketing, ISO 9000, legislação trabalhista, qualidade e exportação.

O Senai, além de consultoria, fornece cursos individuais e/ou coletivos para os funcionários e empresários da incubadora, enquanto o Sesi (Serviço Social da Indústria) possui um centro recreativo e fornece assistência variada. O projeto recorre igualmente a outras instituições para auxílios específicos, como o Instituto de Tecnologia de Alimentos de Campinas, a Universidade Federal de São Carlos (UFSCar) e a Universidade do Estadual Paulista (Unesp).

No que se refere a programas de treinamento, é importante mencionar o papel das empresas de consultoria e das empresas fornecedoras de máquinas e equipamentos. A utilização de empresas de consultoria foi citada por 4 empresas que as contratam para distintas atividades, entre as quais treinamento de funcionários e certificação. A reclamação usual das empresas é o custo elevado das consultorias. O apoio recebido de fornecedores de equipamentos foi citado por 5 empresas, que utilizam regularmente os cursos de operação e manutenção de equipamentos.

No que se refere à relação com instituições do sistema educacional, 9 empresas atribuíram um importante papel ao Senai, seja pela for- 
mação dos aprendizes, como pela oferta de cursos através de suas unidades móveis. Algumas empresas enfatizaram a importância de escolas técnicas, por fornecer estagiários e pelos convênios para a participação de seus funcionários em seus cursos regulares. A relação com universidades foi enfatizada por 6 empresas da amostra, que citaram especialmente a UFSCar, a Universidade de São Paulo (USP) de São Carlos, a Universidade Estadual de Campinas (Unicamp), a Escola de Engenharia de Piracicaba e a Universidade Federal de Santa Catarina (UFSC). As empresas declararam utilizar as universidades para recrutamento/treinamento de engenheiros, cursos de especialização, aferição de instrumentos e uso de laboratórios para a realização de testes. Uma das grandes empresas da amostra citou particularmente a contratação de 2 pós-graduandos de engenharia de produção da USP - São Carlos para auxiliar na implantação de seu sistema de just-in-time/kanban externo. Por sua vez, outra empresa está desenvolvendo novas aplicações de ferramentas juntamente com a UFSC. Dessa forma, pode-se observar o crescimento da interação das empresas com as universidades, principalmente aquelas de maior projeção regional e nacional, que se encontram fisicamente mais próximas. A distância entre esses dois tipos de instituição parece estar diminuindo a partir da existência de novos e crescentes contatos entre elas.

Assim, é possível concluir que iniciativas de cooperação entre diferentes tipos de instituição têm adquirido extrema importância para a sobrevivência e o crescimento de algumas empresas, contribuindo igualmente para sua adequação ao novo cenário de exigências relativas à qualidade de produtos e à qualificação da mão-de-obra, o que indica uma reconfiguração das relações institucionais. Nesse sentido, é possível afirmar que as relações das empresas com diferentes tipos de instituição estão assumindo um papel cada vez mais importante para a sobrevivência e o desenvolvimento de um tecido industrial mais competitivo na região estudada. Nesse novo cenário, crescem a importância e a responsabilidade das instituições do sistema educacional para o desenvolvimento social e econômico da região.

\section{Notas}

1. Para uma visão da utilização do conceito de rede (network), ver como Callon (1992) utiliza a noção de "redes tecno-econômicas"; Sabel (1993) a de "trust"; e Granovetter (1990), a de "embeddedness". Estes conceitos estão inseridos 
em vários debates que se cruzam na literatura dos anos 90. Seu uso ajuda a pensar a reconfiguração das relações institucionais tanto no interior das empresas quanto entre as empresas e as relações entre o sistema produtivo e o sistema educacional.

2. Parte dos resultados do projeto, que tem como objetivo comparar o processo de reestruturação em quatro cadeias produtivas da indústria brasileira, em diferentes regiões do país, com ênfase na análise das mudanças nas relações interfirmas e nos movimentos de externalização/internalização de atividades: a) a indústria de autopeças em Campinas (SP), Rio de Janeiro e Rio Grande do Sul; b) a indústria de linha branca na região de Campinas (SP); c) a indústria de telecomunicações no Rio de Janeiro e d) o cluster produtor de calçados no Vale dos Sinos (RS). A comparação da dinâmica de reestruturação dessas cadeias visa estudar suas conseqüências para a estrutura do emprego, condições de trabalho e qualificação, e a natureza das demandas criadas para o sistema educacional. Trata-se de verificar como se dá a articulação entre a estratégia competitiva das empresas, pressionadas pela dinâmica das cadeias em que estão inseridas, o mercado de trabalho das diferentes regiões onde estão localizadas e as instituições locais.

3. A região de Campinas, formada por 83 municípios, é a mais importante área econômica do Estado de São Paulo após a região metropolitana e caracteriza-se pela existência de um setor industrial extremamente dinâmico, que cresceu mesmo durante a chamada "década perdida". Em 1990, a população da região atingiu 4,5 milhões de habitantes (Negri 1990, p. 88).

4. Para uma discussão da importância do estudo das cadeias produtivas, ver como Gereffi (1995) utiliza o conceito de "cadeias de commodities globais".

5. Os fornecedores diretos realizam atividades que agregam valor ao produto do cliente, enquanto os fornecedores indiretos realizam atividades de apoio à produção, que não agregam valor ao produto.

6. O problema aqui está relacionado não só à natureza da relação com o cliente, como também à possibilidade do cliente conseguir sobreviver ou dar prosseguimento a suas atividades no país. A BCP 1.1, por exemplo, possui uma planta dedicada à BCP 1 , mas também construiu outra planta para fornecer para o principal concorrente deste cliente na cidade onde ele se localiza.

7. A indústria de eletrodomésticos pode ser dividida em dois segmentos: o de eletrodomésticos portáteis e o de não-portáteis (linha branca).

8. A tecnologia de produto nesta indústria é madura, incorporando inovações incrementais relacionadas às mudanças de gosto, hábito e/ou necessidades dos consumidores. Já as inovações de processo estão associadas à difusão da automação microeletrônica e de novas técnicas de planejamento, organização e gestão da produção e da qualidade. 
9. Esta indústria foi implantada no Brasil em fins da década de 1940, na fase inicial da política de substituição de importações de bens de consumo duráveis, seguindo a instalação da Companhia Siderúrgica Nacional (CSN).

10. O mercado mundial de eletrodomésticos de linha branca alcançou um alto grau de saturação em termos de quantidade e/ou renda nos anos 90, especialmente dos eletrodomésticos tradicionais, como refrigeradores e lavadoras de roupa (manutenção da demanda via inovações de produto e menor durabilidade dos aparelhos). A difusão dos não-tradicionais, como lava-louças, secadoras e fornos de microondas, aparece como a principal responsável pela expansão da demanda.

11. No que se refere às relações interfirmas, é importante distinguir entre as relações verticais (complementariedade na cadeia produtiva) e as horizontais, nas quais as relações podem abranger desde a concorrência acirrada até estratégias de colaboração.

12. O just-in-time é um sistema de gestão da produção que visa aumentar a sincronia entre produção e demanda, reduzindo estoques e custos, que pode ser usado no interior de uma empresa (interno) e/ou entre clientes e fornecedores (externo). O volume de produção é determinado pela demanda da operação seguinte realizada interna ou externamente. O kanban é um sistema de cartões que substituem as ordens de fabricação na produção JIT. A implantação do JIT/kanban externo não significa a eliminação de estoques no fornecedor, o que depende da adoção do JIT/kanban interno. O que ocorre nestes casos é o repasse de estoques (e dos custos) do cliente para o fornecedor.

13. Os programas de repasse de atividades antes desenvolvidas por funcionários de uma determinada empresa para "terceiros", ou seja, outras empresas ou instituições que atuam dentro ou fora das instalações da empresa, são chamados de "terceirização". O termo é usado de forma corrente pelos envolvidos em processos de externalização e descreve um conjunto amplo de possibilidades.

14. As exigências de certificação têm causado a revolta de alguns fornecedores, que afirmam não ter condições financeiras para sustentar este processo.

15. Nas 7 empresas que forneceram dados sobre a evolução do emprego e do faturamento observa-se o aumento da produtividade. A planta da BCP tinha 3.000 funcionários e um faturamento de US\$130 milhões em 1980; 3.050 empregados para um faturamento de US $\$ 230$ milhões em 1990, e, em 1996, esta relação era de 2.000 para US $\$ 450$ milhões. Esta planta era muito antiga e os investimentos em novos equipamentos ainda não haviam começado (estavam planejados). Estes resultados estão associados a inovações organizacionais (muitas) e à externalização de atividades.

16. Para gerir processos de externalização, algumas empresas têm utilizado diferentes artifícios para contornar a legislação trabalhista ou mesmo desrespeitála. Essas práticas estão baseadas em relações de confiança entre as partes envolvidas, sem o que, não seriam viáveis. Nem sempre a economia buscada 
por essa via tem trazido resultados satisfatórios, levando algumas empresas a internalizarem novamente atividades que haviam externalizado.

17. Alguns entrevistados não responderam às perguntas sobre relações com os sindicatos por total desconhecimento, o que indica um baixo nível de visibilidade dos sindicatos na região. Ao contrário desta situação, os Sindicatos de Trabalhadores do Grande ABC, onde as grandes montadoras estão localizadas, têm demonstrado uma enorme criatividade e avanços no que se refere à negociação de inovações (Gitahy e Bresciani 1997).

18. Esta fundação foi criada em 1991 como parte de um plano da Organização das Nações Unidas (ONU) para estabelecer um Centro de Qualidade para a América Latina, que acabou não se concretizando. A fundação sobreviveu e se tornou um centro de treinamento para funcionários das empresas participantes (15 empresas participam do programa, pagando uma taxa para sua manutenção). A idéia central do programa é a constituição de formadores de opinião em cada empresa, responsáveis pela difusão das informações necessárias ao desenvolvimento da qualidade. O programa deve incluir a reciclagem de vários tipos de funcionários (via um convênio com a UFSCar), mas ainda se encontra no estágio de palestras para gerentes.

19. Atualmente, existem núcleos em funcionamento e/ou instalação em 54 cidades do Estado de São Paulo. O Núcleo de Iniciação e Desenvolvimento Organizacional (Nido) de Rio Claro, onde se localiza a empresa da amostra, foi formado em fins de 1994.

\title{
Redesigning Institutional Networks: Inter-Firm Relationship, Work and Education in the White Goods Industrial Sector
}

\begin{abstract}
This study analyses the diffusion of technological and organizational innovations within the white goods commodity chain based on a survey of firms close to around the city of Campinas/ SP during the period 1996-1997. It attempts to verify whether the reestructuring process affects inter-firm relations and the relations between the firms and different institutions, specially those related to the educational system.
\end{abstract}

\section{Bibliografia}

CALLON, M. "The dynamics of techno-economic networks" In: Coombs, R., Saviotti, P. e Walsh, V. (1992). Technological change and company strategies: Economical and sociological perspectives. Londres, Harcourt Brace Jovanovich Publishers, 1992. 
CAPECHI, V. "The informal economy and the development of flexible specialization in Emilia-Romagna". In: Portes et alli (eds.). The informal economy: Studies in advanced and less developed countries. Baltimore e Londres, The Johns Hopkins University Press, 1989.

CUNHA, A.M. "A indústria de eletrodomésticos de linha branca". Panorama setorial elaborado para o projeto "Reestruturação Produtiva, Trabalho e Educação”, Finep/CNPq/Cedes. Campinas, 1997, Unicamp.IG/DPCT, (mimeo).

GEREFFI, G. "Contending paradigms for cross-regional comparison: Development strategies and commodity chains in East Asia and Latin America". In: Smith, P., ed. Latin America in comparative perspective: New approaches to methods and analysis. Boulder, $\mathrm{CO}$, Westview Press, 1995.

GITAHY, L. e BRESCIANI, L.P. "Reestruturação produtiva e trabalho na indústria automobilística brasileira", Campinas, DPCT/IG/Unicamp, 1997 (mimeo).

GRANOVETTER, M. "The old and the new economy sociology: A history and an agenda". In: Friedland, R. e Robertson, A.F. (orgs.). Beyond the marketplace: Rethinking economy and society, Nova York, Aldine de Gruyter, 1990.

NEGRI, B. "Diagnóstico setorial: A indústria de transformação no Estado de São Paulo 1970-1990". Relatório de Pesquisa, Campinas, IE/ Unicamp, 1990.

PIORE, M. \& SABEL, C. The Second Industrial Divide. Nova York, Basic Books, 1984.

SABEL, C. "Learning by Monitoring: The Institutions of Economic Development". In: Handbook of Economic Sociology, Princeton, NJ, Princeton University Press, 1993b. 